\title{
Estudos
}

\section{Perfil do Atendimento em Alfabetização de Jovens e Adultos no Estado de São Paulo*}

\author{
Sérgio Haddad Maria \\ Clara Di Pierro \\ Pontifícia Universidade Católica de São Paulo (PUC/SP) \\ Maria Virgínia de Freitas Universidade de São Paulo \\ (USP)
}

Relata conclusões de um estudo sobre a alfabetização de jovens e adultos no Estado de São Paulo, no período de 1988 a 1991. O atendimento revelou-se irrisório em face da demanda potencial por esse serviço educativo. As políticas educacionais nas esferas federal e estadual de governo refluíram. O atendimento na suplência de $1^{a}$ a $4^{a}$ séries do $I^{\circ}$ grau teve modesto crescimento devido às esferas estadual e municipal de governo; as matríadas no ensino privado mantiveram-se estagnadas; a participação da sociedade civil, no aspecto quantitativo, é pouco significativa. Verificou-se uma tendência à superação das ações emergenciais que caracterizaram no passado as campanhas de alfabetização de adultos, com a incorporação de um conceito mais abrangente de educação básica. O rendimento escolar é muito baixo, ainda que se observe uma tendência de melhora dos indicadores de evasão e repetência. Conclui-se que os níveis de qualidade de ensino alcançados não atingiram ainda patamares razoáveis.

-O artigo c uma síntese do relatório da pesquisa de mesmo título desenvolvida pelo Program Educação e Escolarização Popular
do Centro Ecumênico de Documentação c Informação (CEDI), com o apoio do Instituto Nacional de Estudos Pedagógicos (INEP).

R. bras. Est. pedag., Brastlia, v.74, n. 178, p.495-528, set./dez. 1993 


\section{Introdução}

A educação e escolarização de jovens e adultos das camadas populares é um tema que vem ganhando espaço, lenta e gradativamente, nas preocupações de educadores, movimentos sociais e órgãos públicos responsáveis pelas políticas sociais. Tais preocupações, entretanto, não têm resultado em uma ação consistente do Estado na oferta de serviços escolares em quantidade e qualidade necessárias, e tampouco em uma produção de conhecimento sistemática por parte dos organismos de pesquisa e das universidades.

Um conjunto de estudos (Haddad, 1987, 1988a, 1988b, 1989c, 1991) e artigos (Di Pierro, 1990; Haddad, 1987, 1988c, 1988d; Ribeiro et al., 1992; Haddad, Siqueira, Freitas, 1989a e 1989b) configurou um conhecimento significativo das alternativas de escolarização de jovens e adultos no Brasil até o final dos anos 80 , porém mostrou-se insuficiente para compreender as transformações ocorridas com a promulgação da constituição de 1988 e as políticas públicas implementadas nos anos recentes. Esta pesquisa procura dar continuidade a uma linha de investigação iniciada há seis anos pelo Programa Educação e Escolarização Popular do CEDI, atualizando o conhecimento disponível para o novo momento conjuntural.

$\mathrm{Na}$ impossibilidade de realizar novo estudo de abrangência nacional, optou-se por realizar uma pesquisa no âmbito do Estado de São Paulo, pela facilidade de acesso às fontes, pela expressão demográfica e econômica do estado, sua influência exercida sobre o restante do país e seu papel precursor na implementação de políticas educacionais. Esta pesquisa, entretanto, necessitará ser complementada por estudos comparativos em outros estados e regiões do país.

\section{Colocação do problema, objetivos e hipóteses da pesquisa}

A Constituição Federal de 1988 estendeu aos jovens e adultos o direito ao ensino fundamental público e gratuito, ampliando as responsabilidades das redes públicas de ensino no atendimento educacional a esta faixa etária. Essas responsabilidades foram reiteradas pelo Artigo 
60 das Disposições Transitórias, em que a Constituição estabeleceu um período de dez anos ao longo dos quais deveriam concentrar-se os esforços e recursos governamentais e da sociedade civil para a universalização do ensino básico e erradicação (sic) do analfabetismo.

A Constituição Federal compartiu a responsabilidade pela oferta do ensino fundamental obrigatório e gratuito entre as esferas de governo, estabelecendo o regime de colaboração entre os sistemas de ensino, mas abriu flanco à polêmica da municipalização ao mencionar explicitamente que "Os Municípios atuarão prioritariamente no ensino fundamental e pré-escolar" (Art. 211, $\S 2^{\circ}$ ). Uma distribuição mais clara das responsabilidades entre União, estados e municípios acabou sendo postergada para a Lei Complementar de Diretrizes e Bases da Educação Nacional, que desde 89 tramita no Congresso Nacional.

A Constituição do Estado de São Paulo de 1989 fixou, no Artigo 249, que:

$\S 3^{\circ} \mathrm{O}$ ensino fundamental público e gratuito será também garantido aos jovens e adultos que, na idade própria, a ele não tiveram acesso, e terá organização adequada às características dos alunos.

$\S 4^{\circ}$ Caberá ao Poder Público prover o ensino fundamental diumo e noturno, regular e supletivo, adequado às condições de vida do educando que já tenha ingressado no mercado de trabalho.

O cenário desenhado pelos novos textos constitucionais faria supor uma ampliação substancial dos programas de alfabetização de jovens e adultos nos anos subseqüentes, fossem eles mantidos pelas três esferas de governo, pelo setor privado ou por organismos não-governamentais.

Mais pela carga histórica que pela divisão legal dos encargos educacionais, porém, grande parte das expectativas relacionadas à educação básica de jovens e adultos recaía sobre o governo federal, que desde o final dos anos 40 implementou campanhas de educação de adultos e, a partir de 1971, foi o principal mantenedor de programas de alfabetização através do Mobral (1971-1986) e de sua sucedânea, a Fundação Educar (1986-1990).

As expectativas positivas seriam reforçadas nos anos seguintes pelo movimento internacional impulsionado pela Organização das Nações 
Unidas, que declarou 1990 o Ano Internacional da Alfabetização, realizando-se em Jomthien, Tailândia — sob os auspícios da Organização das Nações Unidas para Educação, Ciência e Cultura (UNESCO), do Banco Mundial e do Programa das Nações Unidas para o Desenvolvimento (PNUND) - , a Conferência Mundial que aprovou a Declaração Mundial sobre Educação Para Todos, da qual o Brasil é signatário.

Os fatos contradisseram as expectativas: a Fundação Educar restringiu em 1989 seus convênios de cooperação financeira com os municípios das regiões Sul e Sudeste e, em março de 1990, foi extinta pela Medida Provisória 251, ao início do governo Collor. O governo federal desencadeou a partir de setembro de 1990 o Programa Nacional de Alfabetização e Cidadania (PNAC), que não viria cobrir a lacuna aberta pela extinção da Fundação Educar, em virtude de sua conturbada trajetória (cf Di Pierro, 1992; Luce, Fávero, Haddad, 1992).

Tal fato ensejou a hipótese de que os serviços de alfabetização de jovens e adultos tenham se reduzido a partir de 1990, uma vez que sua principal fonte de sustentação técnica e financeira - a Fundação Educar - deixara de existir. Seria necessário, ainda, investigar se o PNAC tivera algum impacto positivo sobre a oferta de serviços de alfabetização de jovens e adultos.

Observações assistemáticas indicavam que algumas administrações municipais, especialmente aquelas que mantiveram convênios com a Fundação Educar no passado e herdaram serviços de alfabetização de adultos, acabaram por assumi-los e dar-lhes continuidade. Há que se considerar que a redistribuição da receita pública promovida pela Constituição Federal de 1988 assegurou aos municípios um incremento de cerca de $30 \%$ em suas receitas de impostos próprios e transferidos (Melchior, 1992, p.7-8; Mello, Silva, 1992; Xavier, Silva, 1992), aumentando sua capacidade de investimento em educação. Emergia assim uma segunda hipótese de pesquisa: de que os serviços de alfabetização de jovens e adultos tenham se mantido e até mesmo se ampliado após 1988, mediante a assunção de seus encargos pelos municípios.

No que concerne à atuação do governo estadual paulista, a hipótese que emergia é de que o atendimento escolar à população jovem e adulta teria se reduzido a partir de 1991, pois, em contradição com as 
determinações da Constituição Estadual, o governo estadual desencorajou explicitamente a expansão do ensino supletivo. O Programa de Reforma do Ensino Público do Estado de São Paulo determinou: "A política da Secretaria é no sentido de não expandir a oferta de vagas para essa modalidade de ensino, já que o centro de suas preocupações é universalizar o ensino regular" (São Paulo, SEE, 1991, p.13). O problema reside na inexistência de oferta de ensino regular de $1^{\mathrm{a}}$ a $4^{\mathrm{a}}$ séries do $1^{\mathrm{o}}$ grau em período noturno na rede estadual de ensino, o que na prática condiciona, quando não suprime, as oportunidades educacionais de 7,5 milhões ${ }^{1}$ de jovens e adultos trabalhadores que vivem em São Paulo e possuem baixa ou nenhuma escolaridade.

O objetivo da pesquisa foi traçar um perfil do atendimento em alfabetização de adultos no Estado de São Paulo, de 1988 a 1992, de modo a aferir a amplitude, o movimento e a tipologia dos serviços de alfabetização de jovens e adultos mantidos por órgãos públicos, empresas privadas e organizações da sociedade civil, no período posterior à promulgação da nova Constituição Federal. Procurou-se medir o impacto das responsabilidades adicionais conferidas pela Constituição de outubro de 1988, da extinção da Fundação Educar em março de 1990 e da criação do Programa Nacional de Alfabetização e Cidadania em setembro do mesmo ano.

\section{Histórico da alfabetização de adultos no Estado de São Paulo}

Segundo Beisiegel, até meados dos anos 40, o ensino de adultos encontrava-se pouco desenvolvido no Estado de São Paulo, mas já naquela época o governo estadual mantinha Cursos Populares Noturnos de Educação Primária, com dois anos de duração. A essa iniciativa somavamse cursos similares mantidos por prefeituras e entidades particulares, totalizando 702 classes em 1946.

\footnotetext{
${ }^{1}$ Segundo a Pesquisa Nacional por Amostra de Domicílios do IBGE de 1987, dos 24 milhões de paulistas com idade igual ou superior a 10 anos, $11 \%$ encontravam-se na categoria "sem instrução ou menos de um ano de estudo" e $20 \%$ possuíam entre um êtres anos de estudo. Somando-se as duas categorias, $31 \%$ da população paulista com idade igual ou superiora 10 anos possuía nenhuma escolaridade ou escolaridade interior a quatro anos de estudo, constituindo-se em clientela potencial para programas de educação básica de jovens e adultos.
} 
Em 1947, o governo federal deu início à Campanha Nacional de Educação de Adultos, destinando ao Estado de São Paulo recursos para a manutenção de mil classes de ensino supletivo. Esses recursos foram ampliados nos anos subseqüentes, de maneira que em 1950 já eram 2.100 as classes mantidas em convênio com o governo federal. Para implementar a campanha em São Paulo, foi criado, em 1948, o Serviço de Educação de Adultos (SEA). A lei que regulamentou o SEA colocou os recursos materiais e humanos do ensino primário fundamental a serviço da educação de adultos, estimulando o magistério para essa atividade através de gratificações e da atribuição de pontos, válidos para a ascensão na carreira.

Ainda na década de 50, o governo federal desencadeou a Campanha Nacional de Educação Rural que se desenvolveu em Pinhal, Ilhabela, Avare e Apiaí. Em 1958, a Campanha Nacional de Educação de Adultos foi substituída pela Campanha Nacional de Erradicação do Analfabetismo, que teve pequena repercussão em São José dos Campos e em Caraguatatuba. Esses empreendimentos localizados não afetaram substancialmente o ensino supletivo no estado, cujo funcionamento estável se deveu fundamentalmente à atuação do SEA.

No início dos anos 60, a repercussão das idéias pedagógicas de Paulo Freire e a efervescência político-social que o país vivia ensejaram experiências alternativas de alfabetização de adultos, como a promovida em 1963 pela União Estadual dos Estudantes, em Osasco, e a Operação Ubatuba, conduzida em 1964 pelo Movimento de Educação. Com o golpe militar de 1964, esses movimentos de educação popular foram desarticulados.

A concepção tecnicista de educação que passou a prevalecer nos meios oficiais incentivou o desenvolvimento de tecnologias educacionais, dentre as quais as de educação à distância. Em 1969, a Fundação Padre Anchieta, em convênio com o SEA da Secretaria Estadual de Educação, desenvolveu projeto experimental de ensino pelo rádio e pela televisão: o Curso de Madureza Ginasial, destinado à preparação dos candidatos aos exames de madureza. Neste mesmo ano, o SEA foi extinto e substituído pelo Serviço de Ensino Supletivo, criado pelo Decreto 52.324/69. 
Como decorrência da Lei 5.379, de 15/12/67, o Estado de São Paulo estruturou a coordenação do Mobral em 1971, o que já ocorrera em 1970, no âmbito da capital paulistana.

A promulgação da Lei 5.692/71, que instituiu o Ensino Supletivo, ao invés de estimular a ampliação do ensino de adultos, acabou por reduzir o atendimento, ao menos no âmbito da rede estadual de cursos. A ampliação do ensino básico obrigatório para oito anos implicou a multiplicação de salas do ensino diurno e noturno e dos turnos nas escolas, o que acabou por restringir o espaço físico e institucional para os cursos supletivos, que viram suas salas reduzidas de 3 mil para 1 mil em 1977 (Barreto, 1989).

As modalidades de oferta, sem dúvida, diversificaram-se. Já em 1971 foi constituída a Comissão Central de Exames Supletivos, que passou a promover os Exames de Educação Geral em substituição aos de Madureza, e em 1976 deu início à oferta de Exames de Suplência Profissionalizante. Em 1976 teve início, também, a recepção organizada do Projeto Minerva (Suplência de $1^{\circ}$ Grau via rádio), serviço este que perdurou até 1983. Em 1978 foram ao ar as primeiras emissões do Telecurso $2^{\circ}$ Grau, produzido pela Fundação Roberto Marinho em convênio com a Fundação Padre Anchieta. Em 1981 foi a vez do Telecurso $1^{\circ}$ Grau e da instalação do primeiro Centro de Estudos Supletivos no Estado de São Paulo.

Os dados apontam, entretanto, para uma redução do número de salas e matrículas nos cursos supletivos sistemáticos entre 1976 e 1982. Nota-se, também, a crescente privatização desse setor, especialmente nas séries finais do $1^{\circ}$ grau e no $2^{\circ}$ grau.

A equipe responsável pelo ensino supletivo na Secretaria de Educação possuía inúmeras funções de assistência técnica e supervisão, mas estava isenta da criação e manutenção de cursos. A política vigente era a de que a ação do estado deveria ser supletiva, desenvolvendo-se apenas nas regiões e níveis de ensino em que não houvesse atendimento por parte da iniciativa particular ou de outras esferas do setor público. Barreto aventa a hipótese de que tal esvaziamento da rede estadual de 
cursos supletivos resulte de um acordo tácito entre a Secretaria da Educação e o setor privado, mediado pelo Conselho Estadual de Educação, onde o setor privado era majoritariamente representado.

A partir de 1982, com as eleições diretas do governo estadual, a rede de ensino do estado passou a ser pressionada para ampliar a suplência pública, o que passou a realizar especialmente no $1^{\circ}$ grau. Nessa época, ex-alunos do Mobral da capital organizaram-se para reivindicar a continuidade de estudos através da suplência. Em 1985 o Movimento de Educação da Zona Leste reivindicou a abertura de cursos supletivos públicos; no mesmo ano, conquistou as oito primeiras salas de suplência no bairro de Ermelino Matarazzo, na capital.

O crescimento do atendimento público na rede estadual foi perceptível até 1988, com a ampliação da Suplência I (correspondente às séries iniciais do $1^{\circ}$ grau) a taxas de $20 \%$ ao ano, instalação dos cursos de $5^{\mathrm{a}}$ a $8^{\mathrm{a}}$ séries do $1^{\circ}$ grau (a partir do $2^{\circ}$ semestre de 1984), de $2^{\circ}$ grau (a partir de 1987), e de novos CES na capital e no interior. Os níveis de atendimento anteriores a 1970, porém, não haviam sido restabelecidos até 1988. Neste ano, a Prefeitura Municipal de São Paulo ofereceu sozinha muito mais classes e vagas na capital do que a Secretaria Estadual em todo o estado.

Embora a Constituição de 1988 determine a extensão aos jovens e adultos do direito à educação básica pública e gratuita, responsabilizando a União, os estados e os municípios por sua oferta, a cooperação entre as esferas de governo no campo de ensino supletivo não tem se consubstanciado em São Paulo. O Ministério da Educação deixou de repassar recursos aos municípios para a alfabetização de adultos através da Fundação Educar, antes mesmo de ela ser extinta, pela Medida Provisória 151/90.

Os reiterados projetos da Secretaria Estadual da Educação para a melhoria do ensino noturno (cf. Almeida, 1988) e a ampliação do atendimento escolar aos adultos mal saíram do papel, e a dotação do ensino supletivo representa ínfima parcela no orçamento educacional do estado. Assim, os serviços de educação estão sendo "empurrados" para a esfera dos municípios, que quase sempre não dispõem de recursos 
humanos, financeiros e pedagógicos adequados e freqüentemente não possuem sequer rede física de escolas para atender a adultos.

\section{População, urbanização e analfabetismo no Estado de São Paulo}

A alta concentração industrial, sobretudo da grande indústria associada ao capital estrangeiro, vem fazendo do Estado de São Paulo um espaço especialmente propício ao processo de urbanização. Embora a grande indústria esteja concentrada na Região Metropolitana, desde os anos 70 ela vem se expandindo rumo ao interior paulista que, com isso, tem sofrido um processo acelerado de desenvolvimento e transformação.

A mudança atinge inclusive a área rural do estado, sendo que aí a agricultura passa igualmente por grande impacto modernizante para concorrer com os padrões internacionais de exportação, subordinando-se crescentemente à agroindústria c expulsando grande quantidade de mão-de-obra para as cidades do interior e para a Grande São Paulo. (Fundação SEADE apud Barreto, 1992)

Esse processo de desenvolvimento tem levado as populações dos menores municípios, sobretudo as de baixa renda, a migrarem em direção às cidades de economia mais dinâmica, resultando numa diminuição do contingente populacional dos pequenos municípios, paralelamente à concentração populacional, não só na Grande São Paulo, como também nos centros industriais interioranos que se firmaram no período. Segundo os dados do Censo, em 1991,92,8\% dos 31.546.473 habitantes do estado viviam em zonas urbanas. A distribuição da população pelos vários municípios revela a concentração populacional nos grandes centros: $65 \%$ (371) dos municípios paulistas têm menos de 20 mil habitantes e abrigam apenas $9,6 \%$ da população total do estado, enquanto $2 \%$ dos municípios concentram 47,5\% dessa população. Só na Grande São Paulo vivem 15.416.416 pessoas, praticamente a metade da população do estado, e o município da capital, sozinho, reúne $30,5 \%$ dessa mesma população. 
Tabela 1 - Distribuição dos municípios e da população do Estado de São Paulo, segundo o porte do município

\begin{tabular}{|c|c|c|c|c|c|}
\hline & & \multicolumn{2}{|c|}{ Municípios } & \multicolumn{2}{|c|}{ População } \\
\hline Porte & Faixa Populacional & $\mathrm{N}$ & $\%$ & $\mathrm{~N}$ & $\%$ \\
\hline $\begin{array}{l}12 \\
34 \\
5\end{array}$ & $\begin{array}{l}\text { até } 20.00020 .001 \mathrm{a} \\
50.00050 .001 \mathrm{a} \\
100.000100 .001 \mathrm{a} \\
300.000 \text { Mais de } \\
300.000\end{array}$ & $\begin{array}{r}371 \\
105 \\
47 \\
38 \\
11\end{array}$ & $\begin{array}{r}64,86 \\
18,35 \\
8,21 \\
6,64 \\
1,92\end{array}$ & $\begin{array}{r}3.040 .022 \\
3.393 .990 \\
3.393 .417 \\
6.720 .893 \\
14.998 .151\end{array}$ & $\begin{array}{l}9,64 \\
10,76 \\
10,76 \\
21,30 \\
47,54\end{array}$ \\
\hline Total & & 572 & 110,0 & 31.546 .473 & 100,0 \\
\hline
\end{tabular}

Fonte: IBGE. Censo Demográfico 1991.

O processo de urbanização do interior traz conseqüências semelhantes às observadas na Grande São Paulo: as populações de baixa renda são expulsas para a periferia, deteriorando-se rápida e acentuadamente as condições de vida nessas cidades. Nos pequenos municípios a população encontra reduzidas ofertas de emprego, sobretudo naqueles com menos de 5 mil habitantes (23,3\% do total).

A enorme diversidade dos municípios paulistas ressalta a nãocorrespondência direta entre quantidade de municípios e tamanho da população. Daí decorre a necessidade de se trabalhar com a estratificação dos municípios segundo seu porte.

OANALFABETISMOE AESCOLARIZAÇÃODA POPULAÇÃO JOVEME ADULTAEMSÃO PAULO

Segundo os dados do Censo Demográfico de 1991, o Estado de São Paulo possuía 31.546.473 habitantes, o que representava $21,5 \%$ da população brasileira total (que somava 146.917 .454 pessoas). $\mathrm{O}$ crescimento demográfico paulista no período intercensitário (de 1980 a 1991) foi de 25,9\%, o que corresponde a uma taxa de 2,36\% ao ano.

Em 1991 a grande maioria da população paulista — 92,8\% encontrava-se concentrada nas zonas urbanas (contra 88,5\% em 1980), dado que revela a intensidade e a velocidade do processo de urbanização no estado. 
Os dados do Censo de 1991 relativos à instrução da população ainda não se encontraram disponíveis ao encerrar-se este estudo. Segundo a Pesquisa Nacional por Amostra de Domicílios (PNAD), de 1990, o analfabetismo absoluto alcançava 3.707.405 dos paulistas com 5 anos ou mais, o que representava $12,4 \%$ da população total nesta faixa etária. Embora o índice de analfabetismo seja mais elevado nas zonas rurais $(19,7 \%)$ do que nas zonas urbanas $(12,4 \%)$, a ampla maioria dos analfabetos paulistas $(84,6 \%)$ vive em cidades, onde, em tese, o acesso à educação escolar seria favorecido.

Ampliando-se o conceito de analfabeto para a população que tem menos de um ano de estudo (escolaridade absolutamente insuficiente para garantir a aquisição da leitura, da escrita e do cálculo), o contingente de analfabetos na população paulista com idade igual ou superior a 10 anos resultava em 2.514 .792 habitantes (9,5\% do total desta faixa etária), $82,9 \%$ dos quais viviam em zonas urbanas. Em 1990, 8,7\% da população urbana e $17,2 \%$ da população rural do estado, com idade igual ou superior a 10 anos, possuíam menos de um ano de instrução.

$\mathrm{Na}$ faixa etária de 15 anos ou mais, o analfabetismo absoluto alcançava 2.089.573 habitantes do estado, 9,1\% da população desta faixa etária em 1990. Também nesta faixa etária os analfabetos concentram-se nas zonas urbanas do estado (83,7\%), ainda que o índice de analfabetismo nas zonas rurais $(16,4 \%)$ seja bem superior ao encontrado nas zonas urbanas $(9,1 \%)$.

Se consideramos a hipótese do analfabetismo funciona ${ }^{2}$ na população jovem ou adulta com menos de quatro anos de estudo (uma vez que esta seria a escolaridade mínima para assegurar o domínio da leitura e da escrita sem maior risco de regressão ao analfabetismo), verificamos que a população com baixa ou nenhuma escolaridade ampliavase para 7.672.762 habitantes, exatos $29 \%$ da faixa etária de 10 anos ou mais. Assim, conclui-se que quase um terço dos habitantes do Estado de São Paulo conformariam o contingente que potencialmente poderia demandar programas de alfabetização e educação básica de jovens e adultos.

'Sobre o conceito de analfabeto e alfabetizado, cf. Ferrari, 1991 
Embora a incidência de analfabetos em números relativos na população paulista represente um índice baixo em face da média nacional (que é de 14\% na população com 10 anos ou mais), em números absolutos o estado contribui com $12,26 \%$ do total de analfabetos desta faixa etária existentes no país, em conseqüência da elevada concentração populacional em seu território (22,6\% da população nacional), considerados os dados para a faixa etária de 10 anos ou mais da PNAD de 1990, conforme a Tabela 2.

Tabela 2 - Analfabetismo na população de 10 anos ou mais nos estados-1990

\begin{tabular}{l|r|r|r}
\hline UF & Pop. Total & Pop. sem instrução e com um ano de estudos & $\%$ \\
\hline AM & 1.436 .442 & 116.449 & 8,1 \\
PA & 2.624 .031 & 254.876 & 9,7 \\
MA & 5.204 .444 & 1.365 .075 & 26,2 \\
PI & 2.681 .641 & 729.634 & 27,2 \\
CE & 6.512 .345 & 1.893 .166 & 29,1 \\
RN & 2.333 .596 & 519.865 & 22,3 \\
PB & 3.276 .297 & 845.340 & 25,8 \\
PE & 7.413 .896 & 1.518 .118 & 20,5 \\
AL & 2.438 .930 & 715.058 & 29,3 \\
SE & 1.426 .752 & 353.764 & 24,8 \\
BA & 11.806 .807 & 2.964 .022 & 25,1 \\
MG & 15.962 .857 & 1.940 .072 & 12,1 \\
ES & 2.538 .214 & 325.546 & 12,8 \\
RJ & 14.194 .718 & 1.152 .451 & 8,1 \\
SP & 33.187 .414 & 2.514 .792 & 7,6 \\
PR & 9.164 .881 & 1.001 .613 & 10,9 \\
SC & 4.493 .236 & 300.371 & 6,7 \\
RS & 9.241 .571 & 681.626 & 7,4 \\
MT & 1.739 .150 & 230.635 & 13,3 \\
MS & 1.807 .068 & 231.790 & 12,8 \\
GO & 4.968 .085 & 730.946 & 14,7 \\
DF & 1.879 .219 & 122.573 & 6,5 \\
BRASIL & 146.331 .594 & 20.507 .782 & 14,0 \\
\hline
\end{tabular}

Fonte: IBGE. Pesquisa Nacional por Amostra de Domicilios 1990.

Obs: Tocantins, Acre, Rondônia, Roraima e Amapá não constam da PNAD.

Para os municípios paulistas, os dados sobre analfabetismo disponíveis são apenas aqueles do Censo de 1980, bastante desatualizados. 
A variação regional do analfabetismo no Estado de São Paulo apresenta correlação com urbanização e industrialização: os índices de analfabetismo são maiores nas regiões com maior incidência de população rural e as taxas de alfabetização se elevam nas regiões mais urbanizadas e industrializadas.

Tabela 3 - Analfabetismo e população rural por região administrativa $-\mathbf{1 9 8 0}$

\begin{tabular}{l|c|r}
\hline Regiões Administrativas & Analfabetismo* & População Rural** \\
\hline 1. Registro & $3,1 \%$ & $45 \%$ \\
2. Presidente Prudente & $23,7 \%$ & $31 \%$ \\
3. Marilia & $22,8 \%$ & $28 \%$ \\
4. Sorocaba & $\mathbf{2 2 , 4 \%}$ & $29 \%$ \\
5. São José do Rio Preto & $21,7 \%$ & $29 \%$ \\
6. Araçatuba & $21,6 \%$ & $23 \%$ \\
7. Bauru & $21,3 \%$ & $20 \%$ \\
8. Ribeirão Preto & $\mathbf{1 9 , 9 \%}$ & $16 \%$ \\
9. São José dos Campos & $\mathbf{1 9 , 9 \%}$ & $12 \%$ \\
10. Campinas & $18,5 \%$ & $21 \%$ \\
11. Santos & $16,3 \%$ & $5 \%$ \\
12. Grande São Paulo & $\mathbf{1 5 , 9 \%}$ & $3 \%$ \\
Total do Estado & $\mathbf{1 8 , 0} \%$ & $11 \%$ \\
Interior & $\mathbf{2 0 , 2} \%$ & $20 \%$ \\
\hline
\end{tabular}

* População com 5 anos ou + que não sabe ler e escrever, 1980.

** Porcentagem de população rural em 1980.

Fonte: BRASIL. SEPLAN/SEP. Hierarquia das regiões e dos municípios do Estado de São Paulo. Apud FDE. Analfabetismo: o grande não. São Paulo, 1990. p.125.

A variação local do analfabetismo no Estado de São Paulo apresenta duas tendências nítidas: os índices percentuais mais elevados encontram-se em municípios de pequeno porte (menos de 20 mil habitantes), com elevada proporção de população rural em relação à média estadual, localizados fora dos grandes eixos urbano-industriais e distantes dos pólos regionais; já os maiores contingentes de analfabetos em números absolutos situam-se nos municípios mais industrializados e populosos do estado. 
Estudo realizado pela FDE (1990) observa o paradoxo, segundo o qual os municípios com altas taxas de industrialização e urbanização são simultaneamente aqueles em que o número absoluto de analfabetos é maior, ao mesmo tempo em que os índices relativos de analfabetismo são os menores:

Este paradoxo desaparece quando se considera o papel mediador dos indicadores de qualidade de vida. Quando, no âmbito urbano, insinuam-se condições de vida que ainda hoje predominam na zona rural, aí temos Concomitantemente alto analfabetismo. Os dados corroboram a idéia de que houve transferência do perfil rural carreado pela população que, vindo dessas áreas descuradas, fixou-se na periferia física, econômica e social da cidade, com uma terrível agravante: o analfabetismo, que não chegava a ser um limitador de sobrevivência no Brasil "arcaico", rural, é na zona urbana condição que favorece a pobreza absoluta.

\section{Procedimentos de pesquisa}

\section{A COLETA DE ESTATÍSTICAS E AS LIMITAÇÕES DOS DADOS}

A pesquisa desenvolveu-se de abril de 1992 a março de 1993. A etapa de coleta de dados teve por metas: coletar em fontes secundárias dados estatísticos quantitativos e descritivos dos serviços de alfabetização de adultos mantidos pelas redes públicas e privada de ensino; coletar diretamente dados descritivos e quantitativos sobre a alfabetização de adultos no Estado de São Paulo mediante elaboração e aplicação de um questionário-base da pesquisa; assegurar retorno dos questionários mediante elaboração de um cadastro dos agentes de alfabetização de adultos no Estado de São Paulo (órgãos e dirigentes estaduais de educação; órgãos e dirigentes municipais de educação; empresas; organizações nãogovernamentais; igrejas); reunir bibliografia pertinente ao tema.

As estatísticas sobre Suplência I (correspondente às quatro primeiras séries do $1^{\circ}$ grau) no Estado de São Paulo disponíveis para o período analisado (1988-1992) foram fornecidas pelo Centro de 
Informações Estatísticas (CIE) da Secretaria de Estado da Educação (SEE). Recorremos também a dados coletados pela Secretaria Municipal de Educação de São Paulo, que possui ampla rede de suplência.

Os dados coletados pelo CIE são problemáticos, pois a legislação da Suplência I (Sl) é flexível e o regime escolar pode ser semestral ou anual, enquanto as coletas são anuais. O levantamento é realizado apenas em escolas regulares, excluindo, portanto, as unidades escolares que atendem exclusivamente ao ensino supletivo, aí incluídos os cursos mantidos por empresas, igrejas, sindicatos e organizações nãogovernamentais.

Ao confrontarmos os dados referentes à oferta de Suplência I pelas administrações municipais, constantes dessas estatísticas, com aqueles que obtivemos diretamente junto a uma amostra dos municípios do estado, evidenciou-se que a oferta municipal é bem maior que a computada pelo CIE. No ano de 1991, em uma amostra de 145 municípios, identificamos 75 cursos municipais de Suplência I, enquanto o CIE registrou apenas 18 administrações municipais mantendo tais cursos ${ }^{3}$. No caso dos cursos mantidos pela rede estadual de ensino, não ocorre esse tipo de problema pois o CIE faz parte da estrutura da Secretaria Estadual da Educação tendo, assim, acesso a todo o universo das escolas.

Assim, os dados fornecidos pelo CIE permitem-nos traçar um quadro apenas indicativo da oferta de Suplência I junto às escolas que oferecem também cursos regulares.

Os dados referentes aos cursos de alfabetização e pós-alfabetização de adultos mantidos mediante convênios com a Fundação Educar (extinta em 1990) não são captados pelo CIE. O Ministério da Educação é o depositário dos acervos da extinta Fundação. Foi totalmente impossível apurar junto ao MEC sobre os dados do atendimento realizado mediante convênios pela Fundação Educar nos municípios paulistas, tampouco aqueles relacionados ao Programa Nacional de Alfabetização e Cidadania

'Grande parte dos cursos municipais de SI desenvolve-se em salas de aula cedidas por outra rede de ensino ou espaços cedidos por centros comunitários, nao tendo, portanto, seus dados coletados pelo LDE. Mesmo feita essa ressalva, identificamos na amostra da pesquisa, em 1992, 29 cursos municipais funcionando cm instalações escolares da própria rede municipal; no mesmo ano, 0 CIE registra apenas 18 municípios, em todo o estado, nessa situação. 
do Ministério da Educação, ambos indisponíveis à consulta. Os poucos dados que acessamos relativos ao desenvolvimento do PNAC no Estado de São Paulo foram obtidos em pesquisa de material de imprensa (uma fonte à qual não se pode atribuir rigor científico) e depoimentos de membros da Comissão Estadual do Programa.

As duas instituições que reúnem bancos de dados socioeconômicos no Estado de São Paulo são as fundações Serviço Estadual de Análise de Dados e Estatísticas (SEADE) e Instituto Brasileiro de Geografia e Estatística (IBGE). O SEADE opera com dados fornecidos pelo IBGE. Os dados mais atualizados disponíveis no momento seriam os do Censo Demográfico de 1991. Entretanto, o IBGE somente divulgou os dados definitivos do Censo de 91, referentes à população total, por sexo e situação de domicílio. Os demais dados demográficos e socioeconômicos, entre eles os de alfabetização e analfabetismo, não haviam ainda sido processados pelo IBGE. Assim, estruturamos a amostra e procedemos à análise segundo o porte dos municípios paulistas, de acordo com as classes de população, mas não pudemos analisar a relação entre demanda potencial e oferta de escolarização básica de jovens e adultos, e tampouco interpretar os resultados em face de outras variáveis socioeconômicas e demográficas.

As únicas estatísticas universais sobre índices de analfabetismo e alfabetização por faixas etárias disponíveis até o momento são as do Censo de 1980, exaustivamente analisadas no estudo realizado pela Fundação de Desenvolvimento da Educação (FDE, 1990), publicado com o título "Analfabetismo - o grande não".

Trabalhamos, ainda, com os dados amostrais de escolaridade da população estadual da Pesquisa Nacional por Amostra de Domicílios (PNAD) de 1990, publicados pelo IBGE.

\section{A COLETA DIRETA DE DADOS DESCRITIVOS E QUANTITATIVOS}

Com o objetivo de coletar diretamente estatísticas e dados de caracterização do atendimento em alfabetização de adultos, elaboramos um questionário auto-aplicado, remetido pelo correio ao cadastro de agentes. 
O índice de respostas foi de $29,16 \%$, assim distribuídos nas categorias: 168 questionários respondidos, sendo 145 de prefeituras, 4 de empresas, 3 de organizações não-governamentais, 2 de igrejas ${ }^{4}, 1$ de sindicato, 1 de escola particular e 12 de escolas estaduais de primeiro grau ${ }^{5}$. As respostas aos questionários foram codificadas e tabuladas no programa preparado para este fim.

Dos 572 municípios do Estado de São Paulo, 145 responderam o questionário-base da pesquisa, ou seja, um retorno da ordem de $25,3 \%$. Com esse índice de respostas, as proporções encontradas estatisticamente poderão diferir das proporções reais, com $90 \%$ de confiança em, no máximo, $5 \%$.

Distribuindo esses 145 questionários de acordo com o porte dos municípios, percebe-se que o índice de questionários respondidos aumenta acentuadamente conforme o tamanho da população. No caso dos Portes 1 (até 20 mil habitantes) e 2 (entre 20.001 e 50 mil habitantes), o índice de retorno dos questionários foi bastante pequeno e, para que os dados colhidos fossem estatisticamente válidos, tornou-se necessário agregar as duas categorias em um único porte de até 50 mil habitantes.

Tabela 4 - Distribuição dos questionários respondidos

\begin{tabular}{l|l|c|c|c}
\hline Porte & Faixa Populacional & $\begin{array}{c}\text { Total de } \\
\text { Municípios }\end{array}$ & $\begin{array}{c}\text { Questionários } \\
\text { Respondidos }\end{array}$ & \% \\
\hline $1+23$ & até 50.000 & $\mathbf{4 7 6}$ & 66 & 13,86 \\
45 & 50.001 a 100.000 & 4738 & 39 & 82,98 \\
& 100.001 a 300.000 & 11 & 30 & 90,95 \\
& + de 300.000 & & 10 & 25,35 \\
\hline Total & & $\mathbf{5 7 2}$ & 145 & \\
\hline
\end{tabular}

Fonte: CEDI. EEP

${ }^{4}$ As duas igrejas que nos enviaram questionários — uma de Santos e outra do Guarujá — na verdade cedem espaço para o funcionamento de cursos de Sl mantidos pelas administrações municipais. Esses questionários tiveram, então, que ser desprezados: os dados desse atendimento já estavam incluídos nos questionários enviados pelas respectivas prefeituras. 'Alguns municípios que não mantêm atendimento em alfabetização de jovens e adultos encaminharam os questionários ás escolas estaduais que o fazem. Esses questionários foram desprezados, pois seus dados já haviam sido coletados de modo centralizado junto ao CIE/SEE. 
Os dados obtidos, uma vez assim organizados, são estatisticamente representativos de todos os portes, podendo apresentar uma margem de erro de até $10 \%$, com $90 \%$ de confiabilidade.

\section{Resultados obtidos}

\section{QUANTO ÀS ESTATÍSTICAS DOENSINO SUPLETIVOEMSÃOPAULO}

Os parcos resultados, obtidos com o amplo esforço de coleta de dados e reunião de estatísticas sôbre a educação básica de jovens e adultos e o ensino supletivo realizado nesta pesquisa, nos autorizam extrair algumas conclusões e oferecer sugestões aos organismos responsáveis pela coleta de dados e processamento de estatísticas sobre o ensino supletivo e a educação de jovens e adultos no Estado de São Paulo.

Concluímos que os instrumentos de coleta e processamento de dados estatísticos sobre a alfabetização de adultos e o ensino supletivo disponíveis no Estado de São Paulo são insuficientes e/ou inadequados para permitir um acompanhamento e uma avaliação adequados desta modalidade de ensino, de modo a subsidiar a formulação das políticas educacionais para o setor.

O Centro de Informações Educacionais da Assessoria Técnica de Planejamento e Controle Educacional da Secretaria da Educação do Estado de São Paulo é o organismo melhor posicionado institucionalmente e melhor equipado tecnicamente para proceder à coleta e ao processamento desses dados. Entretanto, seria necessário aperfeiçoar seus procedimentos metodológicos, nos seguintes aspectos: direções:

a) Ampliar a cobertura da coleta de dados em pelo menos três

- no sentido de captar o atendimento escolar realizado para além das escolas regulares. O Levantamento de Dados da Educação (LDE) propõe-se captar o atendimento escolar realizado exclusivamente pelas escolas regulares; despreza, assim, todo o atendimento realizado em unidades escolares exclusivas de ensino supletivo (nas quais se enquadram 
muitas unidades escolares das redes particular, municipais e do SESI); são desconsideradas também todas as classes de alfabetização de jovens e adultos e de ensino supletivo instaladas fora dos equipamentos escolares convencionais como creches, escolas de educação infantil, centros de juventude, empresas, centros comunitários, igrejas, etc. Esse mecanismo seletivo de coleta de dados resulta na impossibilidade de mensurar o atendimento efetivamente realizado na educação de jovens e adultos. Seria necessário ampliar esse critério para computar a realidade do atendimento;

- no sentido de captar melhor o atendimento escolar realizado pelas empresas, igrejas e organizações não-governamentais, aperfeiçoando o cadastro das instituições que realizam esse serviço. Cabe considerar que, nas poucas ocasiões em que o CIE capta estes dados, os inclui na categoria "particular". Acreditamos que seria mais adequado distinguir o atendimento escolar propriamente privado (realizado por escolas particulares mediante pagamento do serviço educacional) daquele comunitário, filantrópico ou confessional (realizado por empresas, igrejas, instituições privadas ou entidades civis e no qual o acesso é público e o serviço é gratuito). Esta classificação estaria em maior consonância com a realidade educacional e a legislação em vigor;

- no sentido de captar melhor o atendimento escolar realizado pelas redes municipais de ensino, nas quais detectamos tendências de crescimento. Os dados colhidos na presente pesquisa dão prova cabal de que o atendimento municipal tem sido subestimado nas estatísticas do CIE, o que revela que seus instrumentos de coleta são falhos neste aspecto.

b) Adequar a coleta e o processamento de dados às especificidades da estrutura e do funcionamento do ensino supletivo:

- realizar coletas semestrais dos dados de movimentação escolar, uma vez que a legislação em vigor permite a organização semestral ou anual dos cursos e a abertura de cursos no transcorrer do ano letivo;

- adequar o processamento dos dados a essa diversidade de regimes escolares (o que certamente é uma tarefa tecnicamente complexa), de modo a que se obtenham dados consistentes de matrícula, movimentação e rendimento escolar. 
c) Divulgar os dados do ensino supletivo nos mesmos moldes que o ensino regular, publicando-os nos anuários estatísticos de educação, pois sua omissão representa uma discriminação injustificável.

d) Evitar a duplicação de esforços da SEESP e do MEC na coleta e processamento de dados, hoje existente em virtude da realização de dois levantamentos (LDE e SP2). Isso poderia ser viabilizado pela compatibilização de critérios de ambos os levantamentos, resultando em racionalização de operações e custos e maior eficiência/velocidade na divulgação de seus resultados, a partir de uma colaboração entre as duas esferas de governo.

É imperioso que o Ministério da Educação agilize o processamento e divulgação dos dados estaduais e nacionais do ensino supletivo, permitindo que seja feito um acompanhamento e avaliação desta modalidade de ensino. O timing atual, que faz com que os dados sejam divulgados com um atraso de até cinco anos, compromete qualquer esforço de planejamento e reorientação das políticas educacionais de ensino supletivo.

É de todo irracional que o patrimônio e a memória das ações governamentais na esfera da educação de jovens e adultos sejam desprezados pelos próprios organismos federais responsáveis, dificultando a reconstituição histórica, a avaliação das políticas e, conseqüentemente, o planejamento educacional. Recomenda-se que o Ministério da Educação, através dos seus órgãos centrais e das Delegacias Regionais, zele pelo patrimônio herdado do Mobral, da Fundação Educar e do PNAC, organizando bibliotecas, bancos de dados e referências com os acervos oriundos das instituições extintas ou programas desativados.

A formulação de políticas e o planejamento educacional exigem o conhecimento da demanda potencial pelos serviços educativos, sua distribuição espacial e suas caracterizações socioeconômica e cultural. Neste sentido, seria recomendável que o IBGE agilizasse o processamento dos dados da população paulista colhidos (já com um atraso de um ano) no Censo Demográfico de 1991. 
Recomenda-se que, tão logo o IBGE divulgue tais dados, o Estado de São Paulo providencie um estudo específico relacionado à população jovem e adulta com nenhuma ou baixa escolaridade, nos moldes do analfabetismo, o grande não, realizado tardiamente (pois baseado em dados do Censo de 80) pela Fundação de Desenvolvimento da Educação em 1990. A título de sugestão, considera-se que uma colaboração entre a Fundação Serviço Estadual de Análise de Dados e Estatísticas (SEADE) e Fundação de Desenvolvimento da Educação (FDE) permitiria que tal estudo fosse realizado e divulgado com qualidade, agilidade e eficiência.

QUANTO À ESTRUTURA E AO FUNCIONAMENTO DOS CURSOS DE SUPLÊNCIA I (ALFABETIZAÇÃO E PÓS-ALFABETZAÇÃO DE JOVENS E ADULTOS) NO ESTADO DE SÃO PAULO

Registra-se como tendência positiva a prevalência de cursos de suplência de $1^{\mathrm{a}}$ a $4^{\mathrm{a}}$ séries do $1^{\mathrm{o}}$ grau $(90 \%)$ sobre os cursos que se restringem à alfabetização de adultos $(10 \%)$. Em sua maioria, os cursos têm, pelo menos, dois anos de duração. Este dado é indicativo da superação das ações emergenciais que caracterizaram no passado as campanhas de alfabetização (e nas quais observavam-se elevados índices de regressão ao analfabetismo), em benefício de uma ação educativa mais sistemática, que busca consolidar o processo de alfabetização e assegurar ao educando condições para a continuidade de estudos.

Mesmo entre os cursos que se restringem à alfabetização de jovens e adultos, predomina o regime anual, com duração de oito a doze meses, o que revela a superação de uma concepção ingênua de que o processo de alfabetização possa realizar-se de modo muito acelerado, em poucas horas, semanas ou meses.

A organização e o currículo predominante nos cursos de Suplência I, que inclui o ensino de língua materna, matemática elementar, noções de ciências sociais e naturais e, menos freqüentemente, educação artística e física, são indicativos também da incorporação de um conceito mais abrangente de alfabetização, que transcende o domínio estrito da leitura e da escrita, identificando-se com a noção mais ampla de educação básica. 
QUANTO AO ATENDIMENTO EM ALFABETIZAÇÃO E PÓS-ALFABETIZAÇÃO DE JOVENS E ADULTOS NO ESTADO DE SÃO PAULO

Ainda que se disponha dos dados de escolaridade da população do Censo Demográfico de 1991, os dados colhidos pelo presente estudo e os indicadores disponíveis revelam que o atendimento no primeiro segmento do ensino fundamental à população jovem e adulta no Estado de São Paulo é, atualmente, irrisório em face da demanda potencial por essa modalidade de serviço educativo. As matrículas registradas nas três redes de ensino em 1990 representavam apenas 4,9\% do total de pessoas analfabetas na faixa etária de 15 anos ou mais identificadas pela PNAD 1990.

Registrou-se um modesto crescimento no número de matrículas na Suplência I e no número de municípios que oferecem essa modalidade de ensino entre 1988 e 1991. Em atenção aos tratados internacionais dos quais o país é signatário, às determinações constitucionais da União e do estado, e com os objetivos de democratizar as oportunidades educacionais, assegurar os direitos de cidadania e preparar os recursos humanos para as novas exigências do mercado de trabalho em face da revolução tecnológica em curso, recomenda-se a ampliação substancial do atendimento em educação básica à população jovem e adulta no Estado de São Paulo. Essa ampliação deve basear-se em estudo técnico da demanda e pautarse por um plano que estabeleça metas e meios de curto, médio e longo prazos.

A cooperação entre as esferas federal, estadual e municipal de governo, determinada pela Constituição de 1988 na tarefa de prover o ensino fundamental público e gratuito, independentemente da idade, não tem se consubstanciado no Estado de São Paulo - ao menos enquanto uma política pública deliberada e consciente - no terreno da educação básica de jovens e adultos.

No que concerne ao governo federal, a extinção da Fundação Educar em março de 1990 representou a retração de recursos técnicos e financeiros da União voltados à alfabetização e à pós-alfabetização de jovens e adultos no Estado de São Paulo. Como o Mobral e a Fundação 
Educar empregavam uma sistemática de relacionamento direto com os municípios, sem mediação da rede estadual de ensino, houve uma transferência direta desse encargo da União para os municípios: a ampla maioria dos programas municipais de educação de adultos implantaramse recentemente (a partir de 1989) e resultam da municipalização dos serviços antes mantidos pela Fundação Educar e pelo Mobral.

Embora os dados a esse respeito sejam escassos, não encontramos no transcorrer da pesquisa indícios de que o Programa Nacional de Alfabetização e Cidadania (1990-1991) tenha revertido para o Estado de São Paulo recursos técnicos e materiais significativos, capazes de impulsionar programas de alfabetização, pós-alfabetização ou de ensino supletivo $^{6}$. Os dados disponíveis indicam que a cooperação do governo federal na educação básica de jovens e adultos ao Estado de São Paulo e seus municípios tem se restringido às transferências constitucionalmente obrigatórias de recursos do salário-educação através do Fundo Nacional de Desenvolvimento da Educação (FNDE) ou a reduzidos recursos orçamentários do Tesouro, obtidos mediante apresentação dos Planos de Trabalho Anuais.

As estatísticas disponíveis revelam que, malgrado a omissão do governo federal, o atendimento em educação básica de jovens e adultos (suplência de $1^{\mathrm{a}}$ a $4^{\mathrm{a}}$ séries do $1^{\mathrm{o}}$ grau) no Estado de São Paulo teve crescimento, ainda que modesto, no período de 1988 a 1992. Coube às esferas estadual e municipal de governo propiciar esse crescimento, visto que a rede particular de ensino manteve estagnado ou até mesmo regrediu seus níveis de atendimento no período.

No que concerne às políticas explícitas de educação (ou seja, aquelas expressas em documentos e discursos oficiais), a tendência da cooperação entre estado e municípios em São Paulo é a de progressiva transferência dos encargos da educação básica de jovens e adultos (suplência de $1^{\mathrm{a}}$ a $4^{\mathrm{a}}$ séries do $1^{\mathrm{o}}$ grau) para os municípios, tal como

${ }^{4}$ Deve-se assinalar que essa constatação é válida para o Estado de São Paulo, e não necessariamente para outras Unidades da Federação, pois houve estados que receberam recursos substanciais do PNAC, seja através de convênios do Fundo Nacional de Desenvolvimento da Educação (FNDE) - como foi o caso de alguns estados do Sul —, seja mediante transferências da quota federal do salário educação (em casos do Norte e Nordeste). 
enunciado no Programa de Reforma do Ensino Público do Estado de São Paulo e colocado em prática por portarias que limitam a abertura e a manutenção de classes de suplência nas "escolas padrão" ${ }^{7}$. A redução do número de classes de Suplência I na rede estadual em 1992 é a conseqüência provável dessa orientação do governo do estado, que deve acentuar-se em 1993, visto que o número de "escolas-padrão" praticamente triplicou nesse ano.

Os dados colhidos no transcorrer da pesquisa revelam que, na prática, vinha se estabelecendo nos últimos cinco anos um padrão "involuntário" ou "inconsciente" de cooperação entre estado e municípios no Estado de São Paulo:

- O estado vinha cumprindo uma função distributiva dos serviços de ensino supletivo, mantendo classes (ainda que pouco numerosas) em quase todos os municípios e constituindo-se quase que no único mantenedor desses serviços nos municípios de pequeno porte (de até 50 mil habitantes). É provável que os pequenos municípios do estado, com escassos recursos orçamentários, não venham priorizando a educação básica de jovens e adultos, mesmo porque a demanda social por educação infantil historicamente tem se manifestado com maior vigor. É provável também que, sem dispor de estruturas próprias de atendimento educacional mesmo para outras faixas etárias (pré-escola e ensino fundamental regular), os pequenos municípios não estejam capacitados física, técnica e materialmente para implantar serviços de educação de jovens e adultos no seu atual estágio de desenvolvimento administrativo. É necessário recordar que, embora concentrem apenas $20,4 \%$ da população estadual, os municípios de pequeno porte totalizam $83,2 \%$ das municipalidades paulistas.

- Os municípios de porte médio e grande (especialmente aqueles com mais de 300 mil habitantes), pressionados pelas demandas econômicas

${ }^{1}$ ODiário Oficial do Estado de São Paulo de 23/10/91 n 202, seção I, p. 1, publica a Portaria n ${ }^{\circ}$ 1, da Coordenadoria de Ensino da Grande S3o Paulo (COGESP) nº que limita a abertura de cursos de suplência nas unidades escolares padrão da rede estadual enquanto não for plenamente atendida demanda por ensino regular. Na prática, tal portaria veta o ensino supletivo nas "escolas padrão" da periferia da capital e cidades médias, em que a demanda por ensino fundamenta] se eleva constantemente. 
e sociais decorrentes do acelerado processo de urbanização, favorecidos peia interiorização do desenvolvimento e pela redistribuição da receita pública a partir de 1989, vêm assumindo gradativamente para si a responsabilidade pela oferta de serviços de educação básica de jovens e adultos, cada vez mais amplos, numerosos e profissionalizados. Embora representem menos de $2 \%$ das municipalidades, os 11 municípios com mais de 300 mil habitantes concentram $47,5 \%$ da população paulista.

As constatações acima sugerem um padrão de cooperação entre estado e municípios para uma etapa de transição no processo de municipalização da educação básica de jovens e adultos, processo esse que já está em curso no Estado de São Paulo:

- Ao invés da extinção indiscriminada das classes de Suplência , (como vem tentando implementar a Secretaria Estadual da Educação), o estado poderia manter e ampliar prioritariamente as classes de educação básica de jovens e adultos nos municípios de pequeno porte, capacitandoos progressivamente (e a médio prazo) a assumirem também esse encargo. - A curto prazo, o estado poderia incentivar - mediante a transferência de recursos financeiros, cessão de instalações fisicas e capacitação de recursos humanos - os municípios de porte médio e grande a assumirem os encargos da educação básica de jovens e adultos, favorecendo a criação pelos municípios de serviços (aonde eles ainda não existem) ou sua ampliação (onde já estão instalados).

- A pesquisa não identificou a existência de qualquer fórum especifico de diálogo e negociação entre estado e municípios no concernente à distribuição dos encargos da educação básica de jovens e adultos. Seria recomendável que o relacionamento entre o estado e os municípios paulistas superasse os termos desfavoráveis atuais, pautandose pela negociação e cooperação. Para que essa negociação seja alcançada com êxito, sugere-se a instalação de um fórum no qual estejam representados a Secretaria de Estado da Educação e a União dos Dirigentes Municipais de Ensino, com suporte técnico da Fundação Prefeito Faria Lima (CEPAM), da Fundação para o Desenvolvimento Administrativo Paulista (FUNDAP) e da Fundação de Desenvolvimento da Educação 
(FDE), com a assistência da Comissão de Educação da Assembléia Legislativa do Estado e a participação das entidades representativas do magistério.

O estudo colheu escassos dados relacionados à participação da sociedade civil no atendimento educacional à população jovem e adulta analfabeta ou com baixa escolaridade. Os dados disponíveis indicam que essa participação é, em termos quantitativos, pouco significativa. Delineiam-se, porém, duas tendências positivas:

- Observa-se um crescente interesse do empresariado (materializado nas políticas de recursos humanos das empresas) pela alfabetização e educação básica de seus empregados. As recentes iniciativas do Sinduscom e a crescente demanda pela abertura de classes do SESI etc. são indicadores a confirmar os discursos do empresariado na mídia e organismos de classe. No interior de uma política mais ampla de universalização do ensino básico, seria legítimo que o poder público estimulasse as empresas a adotarem programas de alfabetização para seus empregados, seja mediante assistência pedagógica direta aos programas, seja através de outras formas de incentivo.

- Observa-se que a sociedade civil organizada (em associações comunitárias e filantrópicas, sindicatos de trabalhadores, igrejas etc.) têm respondido positivamente às políticas governamentais que conclamam a sua participação nas tarefas de alfabetização de adultos, desde que lhe sejam propiciados meios e condições de parceria com o estado. Isso pode ser observado tanto no Movimento de Alfabetização de Adultos (MOVA/ SP) quanto no Programa Nacional de Alfabetização e Cidadania (PNAC). Assim, mais que campanhas de apelo genérico à cooperação, os dados da realidade recomendam implementar políticas de parceria entre instituições governamentais e da sociedade civil, cabendo ao Estado assegurar meios financeiros e assessoria técnico-pedagógica, enquanto às entidades cabe mobilizar recursos humanos e meios físicos não convencionais para implementação de programas de alfabetização e pós- alfabetização de adultos. 
Tomando o rendimento escolar como indicador de qualidade do ensino, chega-se a duas conclusões fundamentais:

- Registrou-se uma tendência de melhora nos indicadores de rendimento escolar no período analisado (1988-1991): elevou-se a aprovação, reduzindo-se a evasão e a repetência.

- Ainda que decrescentes, os índices de evasão escolar (33,9\%) e de reprovação $(19,7 \%)$ são extremamente elevados, representando na somatória das três redes de ensino uma perda de mais da metade das matrículas efetuadas nos cursos de Suplência I. Ainda que parcela da evasão possa ser atribuída a fatores extra-escolares, os índices extremamente elevados indicam a existência de fatores propriamente escolares a incidir na desistência do alunado. Depreende-se destes dados que os níveis de qualidade de ensino alcançados não atingiram ainda patamares razoáveis, sendo necessário investir maciçamente na sua melhoria

Os piores indicadores de rendimento escolar foram encontrados na rede estadual de ensino, indicando que os esforços de melhoria de qualidade deveriam aí se concentrar.

Se tomarmos a qualificação do pessoal docente como indicador de qualidade de ensino, verificamos uma tendência positiva: a quase totalidade dos docentes em exercício possui, no mínimo, habilitação para o magistério; a ampla maioria dos programas conta com supervisão ou orientação pedagógica sistemática, realizada por pedagogo ou outro profissional com formação superior. Há, pois, fortes indícios de profissionalização do pessoal docente, indicando estarem superadas concepções do passado (como a que presidiu o Mobral), em que os alfabetizadores eram recrutados independentemente de habilitação profissional. Entretanto, estudos anteriores indicam que os cursos de $2^{\mathrm{C}}$ grau de habilitação do magistério e os cursos superiores de Pedagogia 
negligenciam a temática da educação de jovens e adultos em seus currículos, o que recomenda sejam implementados programas continuados de formação dos professores em exercício.

As condições de trabalho docente, expressas pela jornada de trabalho predominante (inferior a 25 horas semanais) e pelos padrões majoritários de remuneração (entre um e dois salários mínimos) são, para os padrões brasileiros, indicativos de um certo grau de profissionalização da atividade de educador de jovens e adultos. Apesar desta tendência à profissionalização, a maioria dos professores que atuam na educação básica de jovens e adultos não conquistaram contratos de trabalho estáveis, decorrentes de concursos públicos: a ampla maioria dos professores que atuam nas redes municipais é contratada pelo regime da CLT ou em caráter temporário, e apenas um terço é regido pelo estatuto do magistério. Mesmo na rede estadual de ensino, a maioria dos professores que atuam na Suplência I é constituída por professores contratados e, portanto, não concursados. Embora este estudo não contenha dados sobre esse tema, há evidências empíricas de que o magistério na suplência tem se caracterizado por elevada rotatividade de profissionais. Seria recomendável, neste sentido, adotar medidas de fiscalização, visando ao cumprimento da legislação, que determina a aprovação de estatuto para o magistério e a realização de concursos públicos para contratação dos docentes, também para esta modalidade de ensino.

Outro clássico indicador de qualidade do ensino são as condições fisicas das escolas. A precariedade das instalações fisicas continua a caracterizar a educação básica de jovens e adultos. As redes municipais de ensino parecem não dispor de equipamentos escolares apropriados em quantidade suficiente, o que as obriga a instalar as classes de alfabetização e suplência em espaços cedidos por outra rede de ensino (provavelmente salas ociosas da rede estadual) ou em espaços improvisados em creches, pré-escolas, centros comunitários, igrejas etc. Essa precariedade pode repercutir negativamente nas condições de ensino, se privar professores e estudantes de mobiliário e iluminação adequados, acesso a bibliotecas, 
quadras esportivas, laboratórios, equipamentos audiovisuais etc, assim como dificultar a orientação e a supervisão de ensino, dispersando as salas em numerosos equipamentos isolados entre si. Ainda que nas condições atuais de reduzida oferta não se deva descartar a utilização de espaços não convencionais em programas de alfabetização e pósalfabetização de jovens e adultos, dever-se-ia considerar esta faixa etária e modalidade de ensino nos estudos de demanda e expansão da rede física de escolas, bem como privilegiar a utilização de equipamentos escolares ociosos para a instalação das classes de suplência, inclusive mediante cessão de salas de uma rede de ensino a outra.

\section{QUANTOÀ(AUSÊNCIA DE) POLÍTICA DE EDUCAÇÃODE JOVENSE ADULTOS}

Este estudo detectou inúmeras evidências da ausência de uma ação coordenada de educação básica, capaz de articular políticas de expansão e melhoria do ensino fundamental para as faixas etárias infantil, jovem e adulta.

O estabelecimento de diretrizes de politica educacional orientadoras, de âmbito nacional, cabe, constitucionalmente, ao poder executivo federal (através do Ministério da Educação), assistido por conselho (cuja composição e delimitação de atribuições dependem ainda da aprovação da nova Lei de Diretrizes e Bases da Educação).

Os problemas políticos, econômicos e éticos envolvendo o executivo federal desde a aprovação da Constituição, entretanto, resultaram na sucessão de ministros, de prioridades nas políticas educacionais (nem sempre coerentes entre si), na constante alteração das sistemáticas de financiamento e na descontinuidade administrativa das ações ministeriais.

No concernente à educação básica de jovens e adultos, resulta objetivamente desse quadro uma ausência de políticas claras e de regras de cooperação entre as esferas de governo e as redes de ensino.

A falta de diretrizes orientadoras de âmbito nacional e a omissão federal do último qüinqüênio refletiram-se nas políticas de educação básica 
de jovens e adultos do Estado de São Paulo e de seus municípios, também elas caracterizadas pela descontinuidade administrativa, ausência de lineamentos gerais, de regras estáveis de cooperação e coordenação de ações.

\section{Referências bibliográficas}

ALMEIDA, Laurinda Ramalho. O ensino noturno no estado de São Paulo: um pouco de sua história e seus problemas. Cadernos de Pesquisa, São Paulo, n.66, p.49-62, ago. 1988.

BARRETO, Elba S. de Sá. Estado e municípios: a prioridade ao ensino fundamental em São Paulo. Cadernos de Pesquisa, São Paulo, n.83, p. 15-28, nov. 1992.

. O público e o privado na expansão do ensino supletivo em São Paulo. Revista Brasileira de Estudos Pedagógicos, Brasília, v.70, n. 164, p.7-34, jan./abr. 1989.

CONFERÊNCIA MUNDIAL SOBRE EDUCAÇÃO PARA TODOS. 1990. Jomthien, Tailândia. Declaração Mundial sobre Educação para Todos e Plano de Ação para Satisfazer as Necessidades Básicas de Aprendizagem. Brasília: UNICEF, 1990. 20p.

DI PIERRO, M.C. A modernidade na contramão da história. Tempo e Presença, Rio de Janeiro, v.14, n.263, p.21-23, maio/jun. 1992.

$\overline{\text { Revista }}$

Ensino supletivo e universalização da educação básica.

de Educação, São Paulo, n.5, p. 14-17, out. 1990.

FERRARI, Alceu R. Analfabetismo no Rio Grande do Sul: sua produção e distribuição. Educação e Realidade, Porto Alegre, v.16, n.1, p.3-30, jan./ jun. 1991.

FUNDAČÃO PARA O DESENVOLVIMENTO DA EDUCAÇÃO - FDE. Analfabetismo: o grande não. São Paulo, 1990. p.125.

HADDAD, Sérgio. Educação básica para adultos: um direito. Educação $M u-$ nicipal, São Paulo, v.l, n.l, p.33-36, jun. 1988. 
. Educação de adultos: um inicio de conversa sobre a nova lei de educação. Em Aberto, Brasília, v.7, n.38, p.39-44, abr./jun. 1988.

. Ensino supletivo no Brasil, o estado da arte. Brasília: INEP:

'----- REDUC, 1987. 136p.

HADDAD, Sérgio (Coord.). Diagnóstico do ensino supletivo no Brasil: período 1971-1985. São Paulo: CEDI, 1987.

t $\quad$. Diagnóstico dos estudos e pesquisas sobre cursos supletivos Junção suplência — via rádio, televisão e correspondência. São Paulo: CEDI, 1988a.

. Diagnóstico dos estudos e pesquisas sobre políticas, estrutura e funcionamento do ensino supletivo na função suplência: relatório final. São Paulo: CEDI, 1988b.

. Promoção de programas de alfabetização, pós-

- alfabetização e educação de adultos com a vinculação das instituições de ensino superior do Brasil. São Paulo: CEDI, 1989.

Metodologia de alfabetização de adultos no Brasil: o estado da arte. São Paulo: CEDI, 1991.

HADDAD, S., SIQUEIRA, M.C.D.P, FREITAS, M.V. de. 0 ensino supletivo de $2^{\circ}$ grau. Cadernos de Pesquisa, São Paulo, n.68, p.62-69, fev. 1989.

. O ensino supletivo - função suplência: indicações de uma pesquisa. Revista Brasileira de Estudos Pedagógicos, Brasília, v.70, n.166, p.346-370, set./dez. 1989.

LUCE, M.B.M., FÁVERO, O., HADDAD S. A contribuição das comissões estaduais do Programa do PN AC: subsídios para uma avaliação. [S.l.], 1992. 33p.

MELCHIOR, J.C. de A. Financiamento da educação: elementos de análise do ensino fundamental. [S.1.], 1992. 25p. Paper apresentado na reunião de consultores do Pacto peia Infância, promovida peia UNICEF em São Paulo.

MELLO, G.N. de, SILVA, R.N. da. O que pensar da atual política educacional? Em Aberto, Brasília, v.10, n.50/51, p.3-17, abr./set.1992.

RIBEIRO, V.M.M. et al. Metodologia da alfabetização: pesquisas em educação de jovens e adultos. São Paulo: CEDI; Campinas: Papirus, 1992. 128p. 
SÃO PAULO. Secretaria de Estado da Educacãa. Programa de Reforma do Ensino Público do Estado de São Paulo. São Paulo, 1991.

XAVIER, A.C. da, SILVA, L.C.E. O primeiro ano da política educacional do governo Collor. In: DESEP/CUT. A educação e os trabalhadores. São Paulo: Scritta/CUT, 1992. p.79-88.

Recebido em 2 de fevereiro de 1994

Sérgio Haddad, doutor em Sociologia da Educação pela Universidade de São Paulo (USP), é professor do Programa de Estudos Pós-Graduados em História e Filosofia da Educação da Pontifícia Universidade Católica de São Paulo (PUC/SP).

Maria Clara Di Pierro é geógrafa e mestranda do Programa de Estudos Pós-Graduados em História e Filosofia da Educação da PUC/SP.

Maria Virgínia de Freitas é socióloga, mestranda da Faculdade de Educação da USP e professora do Curso Supletivo do Colégio Santa Cruz.

The article presents the conclusions of a research on litteracy among youngsters andadults in the State of São Paulo, Brazil, carried out between 1988 and 1991. The study shows that although schoolplacement inprimmary education institutions for adults and the young had a moderate increase due to initiatives at the state and municipal governement leveis, there were not enough school places in ali tofulfil the potential demandfor this educational service. Both federal and state educational policies receded. Moreover, the enrolment rates in private schools remained stagnant, and the participation of civil Society in this área was, in quantitative terms, rather insignificant. The study also demonstrateda tendencyfor the abandonment of the palliative policies like 
he adult litteracy campaings made in the past, and the development of a more comprehensive concept of basic education. Although a tendency for a decline of the failure and school-leaving rates could be observed, academic achievement was Still very low. The study finally concludes hat the quality of the adult basic education has not asyet reachedacceptable leveis.

L'article décrit les conclusions d'une étude au sujet de l'alphabétization des jeunes et des adultes dans VEtat de São Paulo. L 'assistance était insufisante face à là demande potentielle pour ce service éducatif. Les politiques educatives aux niveaux federal et provincial ont recullé. $L$ 'assistance des adultes au niveau de l 'enseignement primaire a subi un acroissement modéré dual 'action des gouvernements municipal et provincial; les immatriculations dans l 'enseignement prive sont restées figées; Ia participation de là société civil n 'est pas significative sur l 'aspect quantitatif. On a vérifié une tendence à là supération des actions urgentes qui ont caracterize jadis les campagnes $d$ 'alphabétization des adultes, avec le dévelopement d'un concept plus ample d'éducation de base. Le rendement scolaire est três bas, malgré une tendence à là diminution des indicateurs d'évasion et répetence durant là période de 1988-1991. On peut conclure que là qualité d'enseignement $n$ 'a pas atteint des niveaux acceptables.

El artículo relata Ias conclusiones de una investigación relativa a là al/abetización de jóvenes y adultos en el Estado de São Paulo, Brasil, en el periodo 1988-1991. El atendimiento escolar se ha revelado insignificante frente a là demanda por ese servicio educativo. Las políticas educacionales de los gobiernos federal y estadual retrocedieron. El atendimiento a jóvenes y adultos en el nivel primário de instrucción tuvo modesto crescimiento en virtud de là acción de los gobiernos estadual y municipal; las matriculas en là ensenanza privada se han mantenido 
estables; Ia participación de là sociedad civil es poço significativa desde el punto de vista cuantitativo. Se haprobado una tendência a là superaciôn de Ias acciones emergenciales que caracíerizaron en el pasado Ias campanas de al/abetización de adultos, por médio del desarrollo de un concepto más amplio de ensenanza básica. El rendimiento escolar es muy bajo, aunque se observe una tendência de mejora en los indicadores de deserción y repetición. Se impone Ia Conclusión de que là calidad de là ensenanza no alcanzó todavia niveles aceptables. 